\title{
Does shared decision making increase prostate screening uptake in countries with a low prevalence of prostate cancer?
}

\author{
Hussein Saad Amin ${ }^{1}$, Mostafafa Ahmed Arafa ${ }^{2}$, Karim Hamda Farhat ${ }^{2}$, Danny \\ Munther Rabah ${ }^{2,3}$, Abdulaziz Abdullah Altaweel ${ }^{4}$, Abdulaziz Hamed Alhammad ${ }^{4}$
}

\author{
1. Department of Family and Community Medicine, College of Medicine, King Saud University, Riyadh, \\ Saudi Arabia. \\ 2. Cancer Research Chair, College of Medicine, King Saud University, Riyadh, Saudi Arabia. \\ 3. Surgery Department, College of Medicine, King Saud University, Riyadh, Saudi Arabia. \\ 4. Medical Intern, College of Medicine, King Saud University, Riyadh, Saudi Arabia.
}

\begin{abstract}
:
Background: Men over 50 should discuss the benefits and harms of prostate-specific antigen (PSA) testing with their doctors.

Objectives: To investigate whether shared decision making (SDM) increases the uptake of prostate cancer screening practices among Saudi men.

Methods: This community-based study recruited men aged $\geq 50$ years between January and April 2019. Sociodemographic characteristics, history, and current medical condition information were collected. SDM information with regards to prostate cancer screening was discussed.

Results: In total, 2034 Saudi men, aged between 50 and 88 years, agreed to participate in the current study. Prostate examination for early detection of cancer was recommended for 35.4\% (720) of subjects. Of the subjects, $23.3 \%$ (473) reported that the physicians discussed the advantages and benefits of PSA testing, whereas only 5.6\% (114) stated that the physicians explained the disadvantages and drawbacks of PSA testing.

Conclusion: Our findings suggest that less than one fourth discussed the advantages and disadvantages of PSA testing with their physicians; of these, less than one third underwent PSA blood tests. Improvements are needed in SDM for and against PSA screening. SDM does not affect the intensity of PSA testing. Primary health care physicians should be actively involved in the SDM process.
\end{abstract}

Keywords: Decision making; prostate cancer screening; low prevalence countries.

DOI: https://dx.doi.org/10.4314/ahs.v20i4.43

Cite as: Amin HS, Arafa MA, Farbat KH, Rabah DM, Altaweel AA, Alhammad AH. Does shared decision making increase prostate screening uptake in countries with a low prevalence of prostate cancer? Afri Health Sci. 2020;20(4):1870-4. bttps:// dx.doi.org/10.4314/ahs.v20i4.43

\section{Background}

Prostate cancer is one of the major issues related to men's health worldwide. The World Health Organization (WHO) has reported that prostate cancer is the second most commonly diagnosed type of cancer in

\footnotetext{
Corresponding author:

Karim Hamda Farhat,

Cancer Research Chair,

College of Medicine, King Saud University.

ORCID iD: https://orcid.org/0000-0003-1871-2818

Address: Irqah Post Office, PO Box 76047,

Riyadh 11922 (Saudi Arabia)

Email:kfarhat@ksu.edu.sa
}

men and the fifth leading cause of death in men worldwide ${ }^{1}$. It accounts for $6.6 \%$ of the total mortality in men, and by 2030 , prostate cancer is estimated to cause 1.7 million cases and 499,000 new deaths globally ${ }^{2}$.

The incidence of prostate cancer is significantly lower in Saudi Arabia and the Gulf region than in the USA and European countries ${ }^{3}$; however, its incidence has been increasing. In addition, many metastatic cases have been recently diagnosed in patients aged $<50$ years ${ }^{4}$. Over diagnosis and overtreatment of prostate cancer are major concerns at the population level, but it is difficult to ascertain who has been over diagnosed or over treated at an individual level. Policies are needed to decrease over diagnosis and/or to uncouple over diagnosis from overtreatment ${ }^{5}$. 
The benefits and harms of prostate cancer screening have been debatable. Prostate cancer screening does not "save lives" in terms of reducing overall mortality, but it may reduce the risk of prostate cancer mortality. Based on the new US Preventive Services Task Force (USPSTF) guidelines, men aged 50 years and older should discuss the benefits and harms of prostate-specific antigen (PSA) testing with their doctors ${ }^{6}$. This process is called shared decision making (SDM).

\section{Definition of SDM}

"It is the process of interacting with patients who wish to be involved in arriving at an informed, values-based choice among two or more medically reasonable alternatives." Here, "informed" refers to the fact that there is choices, options, and information about benefits and harms of the options are available to the patients. "Value-based" is defined as "what is important to the patient" 7 .

In clinical practice, SDM is often encouraged as the essential constituent of all patient-provider connections with regards to medical and health choices ${ }^{7,8}$; this is because SDM is based on values of patient-centered care ${ }^{9,10}$. SDM is particularly recommended for "preference-sensitive medical decisions" "11 and considered essential for screening and treatment of prostate cancer ${ }^{12}$. Most professional organizations, including the American Cancer Society (ACS), American Urological Association (AUA), American College of Physicians (ACP), and U.S. Preventive Services Task Force (USPSTF), accentuate that PSA testing should not occur before a thorough discussion between the health-care provider and patient about the known risks and potential benefits of the test. Guidelines strongly advise health-care providers to involve patients, principally those at elevated risk of prostate cancer, in a "shared decision making" process about PSA testing ${ }^{13}$.

Studies that document the kinds of conversations men are having with their health-care providers about PSA testing are scarce. Understanding the extent to which men are engaged in SDM is important particularly in our region, in order to help progress toward the healthy men. This study aimed to assess the implementation of SDM, to investigate whether it increased the uptake of prostate cancer screening practices among Saudi men,

\section{Methods}

This community-based study invited the participation of men aged $\geq 50$ years. They were recruited from primary health care outpatient clinics at different hospi- tals, big malls, and through a google survey. Men aged $<50$ years and those with prostate cancer history were excluded from the study. The purpose and rationale of the study were explained to the subjects in detail, and their written informed consent was obtained. They were subjected to a questionnaire that collected data about sociodemographic characteristics; medical history; history of prostate cancer screening, PSA testing, and prostate examination; and present medical condition. SDM information with regards to prostate cancer screening, was discussed in detail with them.

\section{Statistical analysis}

SPSS version 20 was used for analysis. Simple frequency distribution was used to analyze different variables. The chi-square test and unpaired t test were employed to determine the association between qualitative and quantitative data. The significance level was set at $0.05 \%$.

\section{Results}

In total, 2034 Saudi men agreed to participate in the current study. Age of the subjects ranged from 50 to 88 years, with a mean age of $57.9 \pm 8.6$ years. Of the subjects, $89.9 \%$ had a secondary or university degree. Of the subjects, $25.1 \%$ mentioned that they were suffering from prostate-related problems; $95.8 \%$ had benign prostate hyperplasia and prostatitis. Only $4.2 \%$ of subjects mentioned that they had prostate cancer.

Table 1 illustrates the responses of the subjects with regards to SDM statements. Of the subjects, 35.4\% (720) were advised to undergo prostate examination at the age of 50 years for early detection of prostate cancer. Of the subjects, $23.3 \%$ (473) mentioned that the physicians discussed the advantages and benefits of PSA testing, whereas only $5.6 \%$ (114) stated that the physicians discussed the disadvantages and drawbacks of PSA testing. Among the subjects who were advised to undergo PSA testing and prostate examination, $28.9 \%$ (208) underwent the tests whereas $7.9 \%{ }^{14}$ underwent the tests annually. Patients who were advised about the benefits of early prostate cancer examination were significantly younger (mean age, $56.6 \pm 8.3$ years) and had a higher degree of education than those who were not involved in informed decision making (mean age, $60.4 \pm 8.6$ years $)(\mathrm{t}=5.59, \mathrm{p}=0.00)$. Of the subjects, $52.3 \%$ of participants were advised to undergo prostate cancer examination and PSA testing by the urologist, whereas $26.7 \%$ of subjects mentioned that the primary health care physicians had discussed the benefits and harms of PSA testing with them. 
Table 1: Participants' responses regarding shared decision making for early cancer prostate screening

\begin{tabular}{|l|ll|ll|}
\hline Statements & Yes & \% & No & \% \\
\hline $\begin{array}{l}\text { Has your doctor } \\
\text { advised you to } \\
\text { undergo early } \\
\text { prostate cancer } \\
\text { examination? }\end{array}$ & 720 & $(35.4 \%)$ & 1314 & $(64.6 \%)$ \\
\hline $\begin{array}{l}\text { Have you discussed } \\
\text { the benefits and } \\
\text { advantages of PSA } \\
\text { testing with your } \\
\text { physician? }\end{array}$ & 473 & $(23.3 \%)$ & 1561 & $(76.7 \%)$ \\
\hline $\begin{array}{l}\text { Have you discussed } \\
\text { the drawbacks of } \\
\text { PSA testing with } \\
\text { your physician? }\end{array}$ & 114 & $(5.6 \%)$ & 1920 & $(94.4 \%)$ \\
\hline
\end{tabular}

\section{Discussion}

The current study findings add to an increasing indication that SDM is an unusual occurrence in PSA screening. Mostly, PSA screening occurs with partial or no discussion about the associated advantages and disadvantages between the physician and patient. The majority of participants in the current study were not advised about the importance and significance of early prostate cancer examination (at the age of 50 years), were not recommended to undergo PSA testing, and were not provided information regarding the advantages and drawbacks of PSA blood testing.

Ongoing debates have shown that the aim of SDM has not yet been clarified. Some view SDM as a partnership between patient and/or patient care-related parties and physicians or healthcare providers in terms of equally sharing healthcare-related decisions ${ }^{15,16}$. For others, SDM is a procedure that is involved in decision making $^{17}$ or a tactic to integrate preference-sensitive elements in decision making ${ }^{14}$.

The USPSTF recommends that men should have an opportunity to discuss the potential benefits and harms of prostate cancer screening with their clinician and to incorporate their values and preferences in this deci$\operatorname{sion}^{18,19}$.
Different studies on this topic have shown varied results. Fedewa at al. discussed the recent patterns in SDM for PSA testing in the United States and concluded that $58.5 \%$ and $62.6 \%$ of subjects reported that they received $\geq 1$ element of SDM in 2010 and 2015, respectively. However, a shift from only being told about the advantages of PSA testing toward full SDM was observed $^{20}$. Pucheril et al. concluded that, despite the recommendation that physicians should engage patients in the SDM process, less than a third of the subjects were advised about the advantages and disadvantages of PSA testing ${ }^{21}$. A national study in the USA found that most men reported slight SDM during PSA screening and found that the deficiency in SDM was more prevalent in non-screened men than in screened men ${ }^{22}$. Of the Saudi men who received consultations regarding early prostate cancer examination, only $28.9 \%$ underwent PSA testing, of which $7.9 \%$ underwent the test annually (if necessary). One study reported that, among men who underwent PSA testing recently, $58.5 \%$ and $62.6 \%$ reported that they received $\geq 1$ element of SDM in 2010 and 2015, respectively ${ }^{20}$. A combined analysis of two practice-based randomized controlled trials showed that SDM interventions can increase men's knowledge, alter their perceptions of prostate cancer screening, and reduce actual screening. However, these 
interventions may not guarantee an increase in shared decisions ${ }^{23}$.

Primary healthcare physicians did not have a major role in SDM consultation, because only $26.6 \%$ of the respondents mentioned that they discussed the benefits and harms of PSA testing with their physicians. This value could be representative of the physicians' knowledge and attitude toward counselling. It was also found that physicians, particularly primary health care physicians, who were influenced by scientific evidence were likely to practice informed decision making with their patients ${ }^{24}$. This variability in the physicians' use of informed decision making processes can be attributed to their beliefs and attitudes about screening, which in turn could affect their practice techniques and counseling ${ }^{25,26}$. Although most recommendations encourage SDM for prostate cancer screening, finding the time for these discussions in a full practice is difficult.

\section{Limitations}

Firstly, although the subjects represented the Saudi population, the sample size was not big enough; ideally, the study population should have included Saudi men from different regions. Secondly, the timings of consultation and PSA testing were not evaluated; thus, we could not determine whether the consultations were directly responsible for PSA testing. Finally, the issue of late or delayed cancer diagnosis and its relation to SDM was not addressed in this study.

\section{Conclusion}

Our findings suggest that less than one fourth of subjects discussed the advantages and disadvantages of PSA testing with their physicians; of these, less than one third underwent PSA blood tests. Improvements are needed in SDM for and against PSA screening. SDM does not affect the intensity of PSA testing. Primary health care physicians should be actively involved in the SDM process as they are the direct points of contact with the healthcare system for an individual. Future researches should be directed qualitative studies that strengthen the discussions related to prostate cancer screening between patients and their physicians.

\section{Acknowledgment}

The authors are grateful to the Deanship of Scientific Research, King Saud University for funding through the Vice Deanship of Scientific Research Chairs.

\section{Conflict of interest}

The authors have no conflicts of interest to declare.

\section{References}

1. Ferlay J, Soerjomataram I, Dikshit R, Eser S, Mathers C, Rebelo M, et al. Cancer incidence and mortality worldwide: sources, methods and major patterns in GLOBOCAN 2012. Int J Cancer. 2015;136(5):E359-86. 2. Center MM, Jemal A, Lortet-Tieulent J, Ward E, Ferlay J, Brawley $\mathrm{O}$, et al. International variation in prostate cancer incidence and mortality rates. Eur Urol. 2012;61(6):1079-92.

3. Saudi Cancer Registry. 2015

4. Rabah DM, Arafa MA. Prostate cancer screening in a Saudi population: An explanatory study. Prostate Cancer Prostatic Dis. 2010; 13(2):191-4.

5. Active surveillance/watchful waiting? Accessed at: https://www.massachusettsprostatecancercoalition.org/wp-content/uploads/2013/06/Shared-Decision-Making-for-Prostate-Cancer-Screening-McNaughton-Collins.pdf. March 2019.

6. USPSTF Updates guidelines for PSA-Based screening for prostate cancer in older men. Accessed at: https:/ / www.oncologynurseadvisor.com/prostate-cancer/uspstf-updates-guidelines-psa-based-screening-older-men/ article/776333/. March 2019.

7. O'Connor AM, Llewellyn-Thomas HA, Flood AB. Modifying Unwarranted Variations In Health Care: Shared Decision Making Using Patient Decision Aids: A review of the evidence base for shared decision making. Health Affairs. 2004;23(Suppl2):VAR-63.

8. Coulter A, Parsons S, Askham J, World Health Organization. Where are the patients in decision-making about their own care? European Observatory on Health Systems, WHO Regional Office for Europe; 2008.

9. Makoul G, Clayman ML. An integrative model of shared decision making in medical encounters. Patient Educ Couns. 2006;60(3):301-12.

10. Barry MJ, Edgman-Levitan S. Shared decision making - the pinnacle of patient-centered care. $N$ Engl J Med. 2012;366(9):780-1.

11. Stiggelbout AM, Van der Weijden T, De Wit MP, Frosch D, Légaré F, Montori VM, et al. Shared decision making: really putting patients at the center of healthcare. BMJ. 2012;344:e256.

12. Wolf AM, Wender RC, Etzioni RB, Thompson IM, D'Amico AV, Volk RJ, et al. American Cancer Society guideline for the early detection of prostate cancer: update 2010. CA Cancer J Clin. 2010;60(2):70-98.

13. Leyva B, Persoskie A, Taplin SH. Do Men Receive Information Required for Shared Decision Making About PSA Testing? Results from a National Survey. $J$ Cancer Education. 2016;31(4):693-701.

14. Elwyn G, Frosch D, Rollnick S. Dual equipoise shared 
decision making: definitions for decision and behaviour support interventions. Implement Sci. 2009;4(1):75.

15. Charles C, Gafni A, Whelan T. Shared decision-making in the medical encounter: what does it mean? (or it takes at least two to tango). Soc Sci Med. 1997;44(5):681-92.

16. Hepherd HL, Tattersall MHN, Butow PN. The context influences doctors' support of shared decision-making in cancer care. Br J Cancer. 2007;97(1):6-13. 17. Edwards A, Elwyn G. Inside the black box of shared decision making: distinguishing between the process of involvement and who makes the decision. Health Expect. 2006;9(4):307-20.

18. US Preventive services task force. Final recommendation statement: prostate cancer screening. Accessed at: https://www.uspreventiveservicestaskforce.org/ Page/Document/RecommendationStatementFinal/ prostate-cancer-screening1. March 2019.

19. Clinical Preventive Service Recommendation. Prostate cancer. PSA- based prostate cancer screening in men aged 55-69. Accessed at: https://www.aafp. org/patient-care/clinical-recommendations/all/prostate-cancer.html March 2019.

20. Fedewa SA, Gansler T, Smith R, Sauer AG, Wender $\mathrm{R}$, Brawley OW, et al. Recent Patterns in Shared De- cision Making for Prostate-Specific Antigen Testing in the United States. Ann Fam Med. 2018;16(2):139-144.

21. Pucheril D, Fletcher SA, Berg S, Cole AP, Zlatev D, Chang SL, et al. Shared decision making for prostate cancer screening: Reality or farce? J Urol. 2018;199(4):e1105.

22. Han PK, Kobrin S, Breen N, Joseph DA, Li J, Frosch DL, et al. National Evidence on the Use of Shared Decision Making in Prostate-Specific Antigen Screening. Ann Fam Med. 2013;11(4):306-314.

23. Sheridan SL, Golin C, Bunton A, Lykes JB, Schwartz B, McCormack L, et al. Shared decision making for prostate cancer screening: the results of a combined analysis of twopractice-based randomized controlled trials. BMC Med Inform Decis Mak. 2012;12:130.

24. Pommerville PJ, Zakus P. Knowledge and awareness among primary care physicians in Victoria, BC Canada. Aging Male, 2006;9:215-220.

25. Volk RJ, Linder SK, Kallen MA, Galliher JM, Spano MS, Mullen PD, et al. Primary care physicians' use of an informed decision-making process for prostate cancer screening. Ann Fam Med. 2013;11(1):67-74.

26. Arafa MA, Rabah DM, Abdel-Gawad E, Ibrahim FA. Association of physician knowledge and behavior with prostate cancer counseling and screening in Saudi Arabia. Saudi Med J. 2010;31(11):1254-1250. 